\title{
DEND syndrome
}

INSERM

\section{Source}

INSERM. (1999). Orphanet: an online rare disease and orphan drug data base. DEND syndrome. ORPHA:79134

DEND syndrome is a very rare, generally severe form of neonatal diabetes mellitus (NDM, see this term) characterized by a triad of developmental delay, epilepsy, and neonatal diabetes. 